\title{
The Effectiveness of Clothing Pattern Making Training with CAD-based System on Fashion Students
}

\author{
Hamidah Suryani, Imayanti \\ Home Economics Department \\ Universitas Negeri Makassar \\ Makassar, Indonesia \\ hamidah.suryani@unm.ac.id
}

\author{
Muhammad Yahya \\ Automotive Engineering Department \\ Universitas Negeri Makassar \\ Makassar, Indonesia
}

\begin{abstract}
This descriptive research aims to give an overview of the effectiveness of clothing pattern making training with CAD system on Fashion students viewed from the result of knowledge test and performance test and the students' response result. Techniques of collecting data obtained in research were documentation, test, questionnaire and observation. Data analysis technique used were descriptive analysis technique and Gain testing. The result of the research showed that the training of clothing pattern making based on CAD System on Fashion students met the effective criteria based on: 1) the improvement of students knowledge on clothing pattern making categorized as highly improved. The result of Gain testing was categorized as medium and the performance test was categorized as highly improved, 2) more than a half of the students gave positive feedback on the training, instructors, materials, worksheets, and training comfort.
\end{abstract}

Keywords-effectiveness, training, clothing pattern, CAD system

\section{INTRODUCTION}

The development of technology has managed to facilitate, accelerate, and smoothen everyday activities of human life. These advances have also resulted in and enabled the automation of activities in almost all areas of life, driven by rapid advancement of the industry. The Industry 4.0 as a phase of the technological revolution has also changed the way human activity in scale, scope, and timing completion.

The rapid development of the industry, especially in industries related to vocational education, sometimes cannot be followed by the readiness of the vocational education. This gap can be seen in terms of infrastructure, facilities, technology, curriculum, and the teacher competence. Teacher is the key to educational success. However, not all of them can develop themselves with the latest knowledge or skills or up to date, especially if they have to do it self-taught. As a result, the majority of vocational school graduates still need more trainings and not ready for work yet with relatively low adaptability. If this situation continues, our employment situation will worsen, especially in the current era of Industrial Revolution 4.0, where the development and rapid digitalization and automation technology has been applied in all fields.

In the field of vocational school, fashion and technology are two areas whose development is directly proportional, mutually integrated, interlocked and mutually influenced. The current technological developments cannot be separated from the rapid growing fashion world, and seem to have a positive impact on the growth of various industries, including the garment and convection industries. This can be proved by the rapid rise of some computer software designed specifically for producing clothing patterns.

Patterns in the producing apparels is an important part in making clothing. The embodiment of a clothing is always sourced from the cycle of design to the next stage. It takes the pattern as the basis for cutting the material to be sewn in accordance with the desired model. Patterns as the basis for producing apparels, formed from various alloys. Clothing pattern making is the art of designing outline plans or arrangements to sew a fabric. The first step in making the pattern is to take body measurements. In taking measurements for clothing pattern making, there are conditions that should be considered, one of them is when the person who will be measured must wear normal underwear, especially woman, should wear normal pantyhose and bra [1]. In a system of sizes and patterns there is no need to use custom made clothing in order to allow for precise size and made it fit and in accordance with the body shape, especially the male body [2].

Basic Pattern for Women's Apparel is one of the subject materials in the course of Pattern Construction and Pattern Breakage for Fashion students in State University of Makassar. This course is one of the required subjects for Working Expertise (MKB) courses. Therefore, the making of basic pattern for women's apparel delivered by lecturers and made by the students, as the basis in producing clothing patterns for further Fashion Making Courses in the following semesters, such as: Women's Clothing Making Techniques, Clothing Manufacture Technique, and Fashion Exhibition.

Traditionally, the process of making clothing patterns is done on a piece paper by following the size taken from the model or following the pattern of the particular clothing which is still done manually. However, with the development of technology, nowadays, making clothing patterns using paper has shifted to computer. Although this process still involves human labor to operate it, but the existence of such software is helpful to facilitate the overall clothing production process. There are various software for making clothing patterns which are typically used in industries to create clothing patterns, such as Lectra, Gerber technology, Tuka tec, Optitex, CAD, and so on. The existence of those software is one of the easiest and 
does not take much time, and requires only a small amount of human labor compared to the process of making clothing pattern using paper media manually [3].

One of the fashion clothing making media that can be done automatically is to use CAD technology (Computer Aided Design). CAD is a design system using a computer device and design software. This CAD tool allows engineers to plan, model, and evaluate a product accurately before it is manufactured. Patterning using a CAD system aims to minimize the use of paper or paperboard in a pattern, because by using a CAD system, the pattern becomes a digital archive [4]. This CAD program is used by industry for the efficiency and timesaving reasons with auto nesting feature, material usage will be maximized and can be made in a very short time. Doing this traditionally and manually will take all day to get one marker. However, with a CAD system, then this marker will be created in just several minutes. The development of CAD technology as computer software will make it more efficient to produce clothing patterns. Using CAD system, cutting fabric can be done easily and in a fast way [5]. CAD System can make clothing patterns in accordance with the wishes of the user just by choosing the type of clothing, detail variations and size. With this application, making clothing patterns become a lot faster and easier [6].

Based on the result of preliminary study, it was found that in general, the students who have passed the course of Clothing Pattern Making are those who know the technique of making clothing pattern using only Corel Draw and Adobe Illustration. While clothing pattern making using a special application like CAD system have never been learned before, both in college and from other non-formal institutions.

This condition indicates that students need a training as an effort to increase knowledge and skills about clothing pattern making using the CAD system. With the implementation of several new ways, students are expected to be able to create clothing patterns using CAD software, so they can implement the competence of making clothing patterns using CAD System. Training is teaching or giving experience to a person to develop knowledge, skills, and attitudes in order to achieve something desirable [7]. Training is expected to improve behavior or attitude for trainees in order to solve problems encountered to achieve a better level of life [8]. Training is a systematic process to change the behavior, knowledge and motivation of employees to improve the suitability between employee characteristics and job needs [9].

The training process starts with design, implementation, then, evaluation. The results of this evaluation will describe the success or failure of a training. Design is the key determinant of success, as it is in the first stage of the entire training process [10]. Effective training develops skills and anticipate future needs [11]. Most of the objectives of the training is to make the students acquire new knowledge and skills through training. Self learning is not enough for training and it is not effective. The key element is the positive transfer of training, or the extent to which the learning resulted from training transfer to work and causing relevant changes in performance on workers.
Effectiveness is a measure of the success of the interaction process [12]. The effectiveness of the training is based on the training participants' activities, through the training participants' responses and the training participants' learning outcomes after training. Effectiveness is the utilization of a certain amount of resources, facilities and infrastructure, which are consciously established in advance to produce a certain amount of goods for the services of the activities it carries on. Effectiveness shows success in terms of how far the target has been set. If the result of the activity gets closer to the target, the higher its effectiveness [13]. Effectiveness is a suitability between the people who carry out the task with the intended target. That is how an organization managed to obtain and utilize resources as an effort to realize operational objectives [14].

Based on the aforementioned literature, the empirical training of fashion clothing patterns using CAD System in improving the students' skills is highly needed. Students also need this training as a prospective teacher in facing and anticipating technological developments with the global work system that utilizes technology in making clothing patterns.

The purpose of this research is to know the effectiveness of CAD-based clothing pattern making training on the students of Fashion Program of Home Economic Department in Faculty of Engineering of State University of Makassar.

\section{METHOD}

\section{A. Research Design}

This research is a descriptive study conducted to investigate the value of single variable, without making comparison or linking between variables [15]. This research seeks to get a picture of the effectiveness of the clothing pattern making with CAD-based training on the students of Fashion.

\section{B. Sample Size and Sampling Technique}

The population is the object of research that has certain qualities and characteristics set by the researcher to be studied and then drawn its conclusion [15]. Based on this understanding, the population referred to in this study was 30 Fashion students of class of 2015 who have taken the course of Construction of Patterns and Breakage Pattern.

The sample is part of the number and characteristics possessed by that population. In this research, the sampling technique used was the total sampling in which taking all population (30 students) as the sample since the population was less than 100 students [15].

\section{Instruments}

1) Questionnaire

Three sets of questionnaires were employed in this research. They are (a) questionnaire of the respondents' response on the training. This questionnaire aims to know the respondents' difficulties in training and the advantages of joining the training, (b) questionnaire of the respondents' response to the training module. This questionnaire aims to know the respondents' opinion on the language aspect, the 
systematic, practicality and appearance of the module, and (c) a questionnaire of the respondents' response on the worksheets. This aims to know the respondents' thoughts on the language, systematics, benefits, time and material suitability.

\section{2) Learning Outcome Tests}

The test of learning outcomes was used to measure the competence of the trainees' learning outcomes. The test results of the training participants were:

a) Multiple choice test. This test is based on the indicators of achievement of basic competencies that have been set. Meanwhile, to describe the achievement of predetermined indicators, the benchmark reference is based on the level of mastery of training participants on the content of the tested material, so the value obtained reflects the competence level of the trainees' learning outcomes. The steps to compile the competency test result of the training participants are: (1) to determine the grid of competency test based on the basic competency achievement indicator, (2) to prepare the competency test, and (3) to determine the scoring guidance.

b) Performance assessment. This is an assessment done by observing the activities of trainees in performing a task job. The purpose of the performance assessment is to know what the trainee knows and what the trainee is doing. There are several points that need to be considered: (1) the performance steps that trainees are expected to perform for the performance of a component, (2) the accuracy and completeness of the aspects to be assessed, (3) the specific skills required to complete the task, (4) focused on the particular ability of all aspects that can still be observed, (5) the ability to be judged sorted by sequence to be observed, and (6) designing scoring guidelines.

\section{Data Analysis}

The analysis of the effectiveness of the training on clothing pattern making with CAD System is supported by the results of data analysis of two components of effectiveness, namely: (1) the learning outcomes of trainees, (2) and the training participants' responses on the clothing pattern making training with CAD system. Therefore, the data analysis activities of the three components are as follows:

\section{1) Mastery Testing of Training Materials}

The competency assessment of trainees' learning outcome was divided into two parts, knowledge test and performance test. Knowledge tests conducted at the beginning of the training (pre-test) and at the end of the training (post-test) are intended to know and figure out the information about achievement of the training program seen from the competence of the trainees whether the participants master the training materials well or not. The performance test is intended to test the clothing pattern-making skills with CAD System-based in completing the practice in the worksheet.

Classically, the criteria of training competence in learning counted if at least $80 \%$ of all trainees achieve the standard individual learning competencies, meaning that at least $80 \%$ of all trainees earned a minimum score of 70 in a range of $0-100$ scores. The minimum score of 70 is the standard score used in the Home Economic Department on State University of Makassar.

The performance test was conducted by observing the participants' ability using performance score sheets. Assessment criteria refers to the observation of students' practical learning. Participants are categorized as competent when at least $80 \%$ of all participants achieved individual learning competence, meaning that at least $80 \%$ of participants got at least 70 for the range of $0-100$ score. The minimum score of 70 is the standard score and categorized as not competent if the students scored below 70 .

Participants' mastery of training materials was analyzed quantitatively. For quantitative data analysis, descriptive statistic was used aiming to measure the trainees' ability grouped in five scale, based on the standard category techniques set by the Ministry of National Education, as follows:

- $85 \%-100 \%$ or scored $85-100$ is categorized as Excellent;

- $65 \%-84 \%$ or scored $65-84$ is categorized as Very Good;

- $55 \%-64 \%$ or scored $55-64$ is categorized as Good;

- $35 \%-64 \%$ or scored 35-64 is considered as Fair;

- $0 \%-34 \%$ or scored $0-34$ categorized as Poor.

To know the difference of the participant's ability before training and after training, it can be analyzed descriptively using Gain testing [16]. Statistically stated as follows.

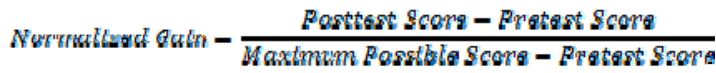

With the criteria of normalized gain level as presented in the Table I.

TABLE I. NORMALIZED GAIN LEVEL CRITERIA

\begin{tabular}{|l|l|}
\hline \multicolumn{1}{|c|}{ Normalized Gain } & \multicolumn{1}{c|}{ Conclusion } \\
\hline $\mathrm{g}>0.7$ & High \\
\hline $0,3<\mathrm{g}<0.7$ & Medium \\
\hline $\mathrm{g} \leq 0.3$ & Low \\
\hline
\end{tabular}

\section{2) The Analysis of Participants' Response Data}

The participants' response on the implementation of the clothing pattern making training with CAD system is divided into six aspects: (1) response on training, (2) response on the material; (3) response on modules; (4) response on the worksheet; (5) the response on the instructors; (6) and response on the comfort/ convenience of the clothing pattern making training with CAD system.

The analysis of participants' response in the two aspects was relatively similar, as the following steps: (1) calculate the number of participants who respond positively according to the aspect asked, (2) calculate the percentage of the first point, (3) determine the category for the participants' positive responses by matching the percentage results to the defined 
criteria, (4) if the results of the analysis indicate that the participant's response has not been positive, a revision of the device is being developed or giving direction to the instructor related to the aspects whose value less.

The criteria set out to state that the participants represented positive responses to training, materials, modules, worksheets, instructors, and comfort to the implementation of the CAD System-based clothing training was more than $50 \%$ of them responded positively to a minimum of $70 \%$ items in the questionnaire.

The data obtained was translated by the following percentage formula:

\section{$\mathrm{P}=$ Error! Reference source not}

$$
\text { found. } \%
$$

Where:

P: Percentage

f: Frequency

$\mathrm{N}$ : The sum of all values

\section{RESUlt AND DisCUSSION}

\section{A. Research Result}

The effectiveness of the training with CAD System on the Fashion students was shown by the participants' responses to the training, and the participants' learning outcomes during the training. The effectiveness of training is presented as follows.

1) The Response of The Participants in Clothing Pattern Making with CAD System.

The response of participants on the clothing pattern making with CAD System is divided into five aspects: (1) response on training; (2) Response to material, (3) Response to Module; (4) response to the worksheet; and (5) response to comfort.

The results of the participants' response to the clothing pattern making training with CAD system are shown in Table II.

TABLE II. PARTICIPANTS' RESPONSES ON THE CLOTHING PATTERNMAKING WITH CAD SYSTEM

\begin{tabular}{|c|c|c|c|}
\hline \multirow{3}{*}{ No } & \multirow{3}{*}{ Aspects } & \multicolumn{2}{|c|}{ Response } \\
\hline & & Yes & No \\
\hline & & $\%$ & $\%$ \\
\hline 1. & Response on training & 100 & - \\
\hline 2. & Response on material & 91,67 & 8,33 \\
\hline 3. & Response on module & 97,95 & 2,05 \\
\hline 4. & Response on worksheet & 100 & - \\
\hline 5. & Response on instructors & 97,15 & 2,85 \\
\hline 6. & Response on comfort & 100 & - \\
\hline & Average & 97,80 & 2,20 \\
\hline
\end{tabular}

Table II shows that all participants gave positive response to the training with CAD system, the provided worksheets, and the comfort during the training session. The majority of the participants gave positive response on the materials given during the training $(91.67 \%)$. A little higher than training materials aspect, $97.95 \%$ of the participants gave positive response on the modules used in training. Similar to this,
$97.15 \%$ participants were satisfied with the way the instructors deliver the materials. These results showed that the training does not only for students who are interested in developing themselves, gaining new knowledge and skills but also for those who seek for external motivation and inspiration to innovate.

\section{B. Evaluation of the Participants}

1) The Result of Knowledge Test

Based on data analysis of pre-test result, participant knowledge can be seen in Table III below.

TABLE III. RESUlt OF KNOWLEDGE IN ClOthing PATtern MAKING WITH CAD SYSTEM IN PRE-TEST

\begin{tabular}{|l|c|c|c|}
\hline \multicolumn{1}{|c|}{ Criteria } & $\begin{array}{c}\text { Score } \\
\text { Interval }\end{array}$ & F & $\begin{array}{c}\text { Percentage } \\
(\mathbf{\% )})\end{array}$ \\
\hline Excellent & $85-100$ & 0 & $0 \%$ \\
\hline Very Good & $65-84$ & 0 & $0 \%$ \\
\hline Good & $55-64$ & 3 & $10 \%$ \\
\hline Fair & $35-54$ & 13 & $33 \%$ \\
\hline Poor & $0-34$ & 14 & $47 \%$ \\
\hline \multicolumn{2}{|c|}{ Total } & 30 & \\
\hline
\end{tabular}

The result of post-test data analysis of trainees' knowledge is shown in Table IV.

TABLE IV. RESUlt OF KNOWLEDGE IN CLOTHING PATTERN MAKING WITH CAD SYSTEM IN POST-TEST

\begin{tabular}{|l|c|c|c|}
\hline \multicolumn{1}{|c|}{ Criteria } & Score Interval & F & $\begin{array}{c}\text { Percentage } \\
(\%)\end{array}$ \\
\hline Excellent & $85-100$ & 3 & $10 \%$ \\
\hline Very Good & $65-84$ & 14 & $47 \%$ \\
\hline Good & $55-64$ & 13 & $43 \%$ \\
\hline Fair & $35-54$ & 0 & $0 \%$ \\
\hline Poor & $0-34$ & 0 & $0 \%$ \\
\hline \multicolumn{2}{|c|}{ Total } & 30 & $100 \%$ \\
\hline
\end{tabular}

Table III shows the results of data analysis for pretest in knowledge of clothing patterns making with CAD System that $47 \%$ of training participants were categorized as poor, $33 \%$ of them were categorized in fair, and $10 \%$ of all participant were categorized as having a good knowledge in clothing pattern making with CAD system. This shows that the participants' knowledge about the clothing pattern making with CAD System in pre-test is still low.

Table IV shows the results of data analysis for post-test in knowledge of clothing patterns making with CAD System that $43 \%$ of the participants were categorized as good, $47 \%$ of them were categorized in very good, and $10 \%$ of all participant was categorized as having an excellent knowledge in clothing pattern making with CAD system. This shows that the participants' knowledge about the clothing pattern making with CAD System after joining the training has increased $(80 \%)$ and higher that the standardized score $(70 \%)$.

Based on the result of knowledge test, the following graphic is the comparison of pre-test and post-test on knowledge in clothing pattern-making training with $\mathrm{CAD}$ System. 
In order to know the comparison of participants' knowledge before and after joining the training, Normalized Gain Test was used to analyze descriptively.

Following the calculation, the average normalized gain was 0.37 and categorized as medium. Therefore, from the descriptive data and normalized gain data, the improvement of participants' knowledge level was categorized as medium. Their score in pre-test was 43.5 and their post-test was 80.3.

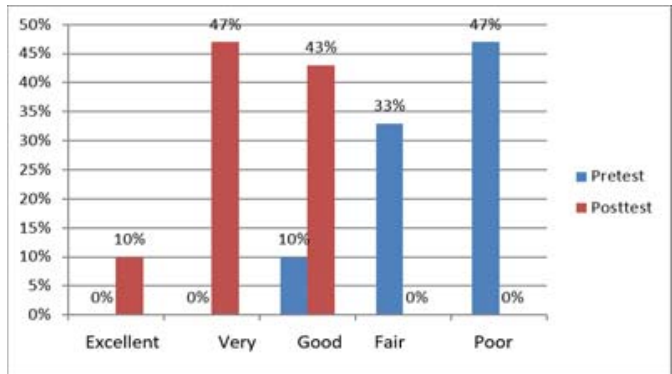

Fig. 1. Bar Chart of Pre-test and Post-test of Participants' knowledge in clothing pattern making with CAD system

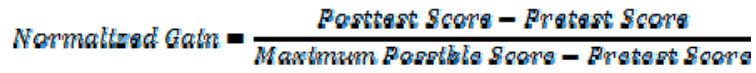

TABLE V. CRITERIA LEVEL OF NORMALIZED GAIN

\begin{tabular}{|c|c|}
\hline Normalized Gain & Criteria \\
\hline $\mathrm{g}>0.7$ & High \\
\hline $0.3<\mathrm{g}<0.7$ & Medium \\
\hline $\mathrm{g} \leq 0.3$ & Low \\
\hline
\end{tabular}

$$
\text { Wormalig Gain }=\frac{888-261}{600-261}
$$

$$
\text { Wopmalised } \operatorname{san}=\frac{12 \pi}{889}=0,87
$$

\section{2) The Result of Performance Test}

The assessment of performance test was conducted by observing the participants in practice. The result of the observation is shown in the Table VI.

TABlE VI. Result of PeRformance Test in Clothing PATtern MAKING WITH CAD SYSTEM

\begin{tabular}{|l|c|c|c|}
\hline \multicolumn{1}{|c|}{ Criteria } & Score Interval & F & $\begin{array}{c}\text { Percentage } \\
(\%)\end{array}$ \\
\hline Excellent & $85-100$ & 11 & $36.7 \%$ \\
\hline Very Good & $65-84$ & 14 & $46.7 \%$ \\
\hline Good & $55-64$ & 5 & $16.6 \%$ \\
\hline Fair & $35-54$ & 0 & $0 \%$ \\
\hline Poor & $0-34$ & 0 & $0 \%$ \\
\hline \multicolumn{2}{|c|}{ TOTAL } & 30 & $100 \%$ \\
\hline
\end{tabular}

Table VI shows that among 30 participants, 11 of them $(36.7 \%)$ were categorized as excellent, 14 participants $(46.7 \%)$ were categorized very good, and 5 participants $(16.6 \%)$ were categorized good. The average of performance test was 79.2 and it was categorized as very good.

The result from knowledge test and performance test in clothing pattern making with CAD system showed that this training meets the effectiveness criteria where $80 \%$ of the participants scored at least 70 .

The effectiveness of the clothing pattern making training with CAD system that has been explained includes the learning outcomes of participants and the participants response on the training can be further described as follows:

\section{The result of Participants' Learning Outcomes}

The effectiveness of the training is seen from the learning outcomes of the participants. The learning outcomes of the participant had improved in knowledge domain. This improvement is seen form the average pre-test score (43.5), their post-test score (80.3), and the gain test was 0.37 . These results showed that the participants' have quite good knowledge on clothing pattern making using CAD system. The results of performance test showed that 11 of the participants $(36.7 \%)$ were categorized as excellent, 14 participants $(46.7 \%)$ were categorized very good, and 5 participant $(16.6 \%)$ were categorized as good. These results proved that the knowledge test and performance test of the participants showed that this training meets the effectiveness criteria since $80 \%$ of the participants scored at least 70 .

Based on the learning outcomes of the participants in making clothing pattern with CAD system, it is concluded that: (1) the ability of the instructors to manage the learning process is done very well; (2) the activities of the participants are included in the category of good and effective for the listening the course and practice; (3) the participants in solving the practical problem in the worksheets have been understood and implemented appropriately on each activity of practical exercise; and (4) instructors and participants are motivated and enthusiastic to follow practical lessons. Learning is effective, when the students are actively involved in organizing and discovering the information (knowledge) and linking the discovered information [17].

\section{Participants Response on the Training}

The participants' response on the clothing pattern-making training with CAD system is divided into six aspects: (1) response on training, (2) response on the material; (3) response on modules; (4) response on the worksheets; (5) the response on the instructors; (6) and response on the comfort/ convenience of the training.

The response showed that the participants were satisfied with the provided module and worksheets as well as enjoying the training atmosphere and materials. Participants thought that this is a kind of new thing for them. Therefore, they are so enthusiastic and actively participate in the training. A training is effective when the learning process is fun and satisfying which will motivate the participants to learn more and practice. Conversely, if the participants are disappointed, they will not be motivated to continue the training. In other words, 
it can be interpreted that the success of the training process cannot be separated with the interest, attention, and motivation of the participants in following the training activities. People will learn better when they react positively to the learning environment [18].

\section{CONCLUSION}

It can be concluded that the training of clothing pattern making with CAD System to Fashion students meet the effective criteria based on The level of improvement of participants' knowledge, which is marked from the pre-test score of 43.5 and increase in the post-test with 80.3 points. The gain test result was 0.37 . This shows an increase in participants' knowledge and categorized as medium. The performance tests scored very good with average score of 79.2. All of the participants $(100 \%)$ gave positive response to the training, worksheet and comfort, $91.67 \%$ of them responded positively to the training materials, $97.95 \%$ of participants gave positive responses to the training module, and $97.15 \%$ of participants gave positive responses to instructors.

\section{REFERENCES}

[1] Elizabeth Bye, Karen L. LaBat, Marilyn R. DeLong. Analysis of Body Measurement Systems for Apparel. Clothing \&'Textiles Research Journal. VOLUME 24 (2). PP 66-79, 2006.

[2] Hosum Lim. Automatic Pattern Generation Proses For Made-toMeasure. Journal of Textile and Apparel Technology and Management. Vol 7 Issue 4 Fall 2012. PP 1-11, 2012.

[3] Kamrun Nahar Naznin , Md. Tabraz , Summiya Sultana. Process \& Effective Methods of Pattern Making For the RMG (ReadymadeGarment) Sector . IOSR Journal of Research \& Method in Education (IOSR-JRME) Vol 7, Issue 3 Ver. II (May - June 2017), PP 46-48, 2017.

[4] Shalini Singh, Rajeev Singh.. Development of a CAD Tool for Pattern Making of Garments. International Journal of Innovative Computer
Science \& Engineering. Volume 4 Issue 2; March-April-2017; PP 11-15, 2017

[5] Ming Lu, Jun dan Mao-Jiun J. Wang. A Computer-aided Production System for Mass Customization in Fashion. Scientific Journal of Riga Technical University Computer Science. Applied Computer System Volume 46, PP 104-109, 2011.

[6] Anikweze, G.U. 2012. The Challenges of Pattern Drafting and Large Scale Garment Production In Nigeria. PAT;Vol 8 (2). PP 11-24, 2012

[7] Wadin, Wahiruddin.. Konsep dan Strategi Pelatihan Menuju Perbaikan Perilaku dan Organisasi. Serunai Jurnal Pendidikan, 3 (1), Hal. 85-92, 2006.

[8] Notoatmodjo, Soekidjo. 2009. Pengembangan Sumber Daya Manusia. Jakarta: Rineka Cipta.

[9] Wiwik Indah Kusumaningrum, Wahyu Hardyanto, Murwatiningsih. Model Manajemen Pelatihan Berbasis Partisipatif. Jurnal Penelitian Tindakan Sekolah dan Kepengawasan Vol. 1, No. 2, PP.80-88, 2014.

[10] Kamil, Mustofa. 2010. Model Pendidikan dan Pelatihan. Bandung: Alfabeta.

[11] Smitt, Rebecca, Rohan Jayasuriya, Peter Caputi and David Hammer. International Journal of Training and Development, Vol. 12 (1).PP 1360-3736, 2008.

[12] Rohmawati, Afifutu.. Efektivitas Pembelajaran. Jurnal Pendidikan Usia Dini. Vol 9 no. 1. PP.15-32. 2015.

[13] Othenk. (2008). Pengertian Efektivitas dan Landasan Teori Efektivitas. http://literaturbook.blogspot.co.id (Accessed on 2 January 2018)

[14] Mulyasa. 2013. Manajemen Pendidikan Karakter. Jakarta: PT. Bumi Aksara.

[15] Sugiyono. 2008. Metode Penelitian Kunatitatif Kualitatif dan R\&D. Bandung Alfabeta.

[16] Meltzer, David E. 2002. The Relationship Between Mathematics PreparationAnd conceptual learning gain in physics: A possible inhidden Variablei in Diagnostic pretest scores. Ames: Department of physics and Astronomy, Iowa State University . on line http://www. physicseducation.net/docs/Addendum_on_normalized_gain.pdf. accessed on 20 January 2018

[17] Eggen, P.D., \& D.P. Kauchak . 2006. Strategies For Teachers: Teaching Content and Thinking Skills. Boston: Allyn \& Boston

[18] Farida Yusuf Tayibnapis. 2000. Evaluasi Program. Jakarta: Rineka Cipta. 